\title{
Nonsuicidal Self-Injury: A Review of Current Research for Family Medicine and Primary Care Physicians
}

\author{
Patrick L. Kerr, PhD, Jennifer J. Mueblenkamp, PhD, and James M. Turner, DO
}

Self-injury is a dangerous behavior that is different from suicidal behavior but is associated with increased risk of suicide attempts. Some effective psychological treatments for self-injury exist. Physicians in family medicine and primary care settings play a vital role as a first step in the treatment process for those who selfinjure. Physicians can enhance the care provided to those who self-injure via the accurate assessment of risk, the understanding of the functions of the behavior, assisting the patient in identifying motivations for treatment and treatment options, and provision of long-term behavioral and risk monitoring. This article summarizes the current scientific knowledge regarding the clinical features, epidemiology, assessment methods, and existing treatments of self-injury. The role of the primary care physician in the treatment of patients who self-injure is specifically outlined. ( $\mathrm{J}$ Am Board Fam Med 2010;23:240-259.)

Keywords: Nonsuicidal Self-Injury, Self-Injury, Risk Assessment, Behavioral Science, Psychiatric, Primary Health Care, Review

Nonsuicidal self-injury (referred to from here forward as "self-injury") is any intentional, self-directed behavior that causes immediate destruction of body tissues. This behavior is manifested in a variety of forms, such as cutting, skin carving, burning, severe abrading/scratching, and punching/hitting. Self-injury can also include more severe behaviors, such as bone-breaking and, more rarely, auto-amputation or ocular enucleation. ${ }^{1}$ Chronic self-injury is associated with a variety of potential health problems, both psychiatric and somatic, and even occasional superficial self-injury may lead to more serious medical complications.

Empirical research suggests that there is currently a trend toward an increasing prevalence of self-injury, especially among adolescents and young

This article was externally peer reviewed.

Submitted 8 May 2009; revised 8 October 2009; accepted 12 October 2009.

From the Department of Behavioral Medicine and Psychiatry, West Virginia University School of Medicine, Charleston Division (PLK); the Department of Psychology, University of Wisconsin-Eau Claire (JJM); and the Departments of Emergency Medicine and Geriatrics, Charleston Area Medical Center, Charleston, West Virginia (JMT).

Funding: none.

Conflict of interest: none declared.

Corresponding author: Patrick L. Kerr, PhD, 3200 MacCorkle Avenue, SE, Department of Behavioral Medicine and Psychiatry, West Virginia University School of Medicine, Charleston, WV 25304 (E-mail: PatrickLKerr@ gmail.com). adults. ${ }^{2,3}$ This potential increase in prevalence makes it highly likely that general practitioners will become the first point of contact for an increasing number of patients presenting with self-injury. This possibility is made even more probable by the current trend of patients seeking treatment for behavioral disorders from family medicine and primary care physicians (FM/PCPs) first. ${ }^{4}$

Strong emotional reactions to someone's disclosure of self-injury are common and understandable. This is true among the general public, medical professionals in all disciplines, and some behavioral health care providers despite their extensive training in the treatment of behavioral disorders. ${ }^{5-9}$ For both mental health care providers and general practitioners, understanding self-injury is a prerequisite for moderating potential negative visceral and emotional responses and for developing an effective plan for treatment. This article provides an introduction to the phenomenon of self-injury and a summary of brief in-office strategies that FM/PCPs can use to help patients who injure themselves.

\section{Epidemiology of Self-Injury \\ Prevalence}

The best research available indicates that self-injury occurs in approximately $1 \%$ to $4 \%$ of adults in the United States, with chronic and severe selfinjury occurring among approximately $1 \%$ of the 
population. ${ }^{10,11}$ Adolescents in general seem to be at an increased risk for self-injury, with approximately $15 \%$ of teens reporting some form of selfinjury. ${ }^{12-16}$ In addition, there seems to be a higher risk for self-injury among college students than among the general population, with rates ranging from $17 \%$ to $35 \% .^{3,17}$ Research suggests that selfinjury rates may be as high as $22 \%$ among primary care patients, although research among primary care populations has been scant. ${ }^{18}$ Aggregated research has found generally similar rates of selfinjury between men and women, although men more frequently report burning and hitting themselves, whereas women are more likely to report cutting and burning themselves. ${ }^{3,10-11,13,19}$

\section{Psychiatric Disorders and Self-Injury}

The presence of psychopathology elevates the probability of self-injurious behaviors and thoughts, and self-injury is associated with more symptoms and greater severity of psychopathology among both men and women. ${ }^{19,20}$ Approximately $2 \%$ to $20 \%$ of psychiatric populations, in aggregate, report self-injury. ${ }^{10,21,22}$ For reasons not fully understood, adolescent psychiatric patients are more likely to injure themselves, with prevalence rates ranging from $40 \%$ up to $80 \% .^{23-27}$ Although psychiatric patients are more likely to engage in self-injury, this varies by the type and severity of their disorder. Specific psychiatric disorders are associated with higher rates and risk for self-injury.

\section{Borderline Personality Disorder (BPD)}

Approximately $70 \%$ to $75 \%$ of individuals with BPD exhibit self-injury. ${ }^{28-30}$ Self-injury is 1 of 9 criteria for $\mathrm{BPD}$; this is the only psychiatric disorder for which self-injury is a diagnostic criterion. Research strongly indicates that self-injury helps to regulate emotions in individuals with $\mathrm{BPD}$; up to $96 \%$ of patients with BPD who self-injure report relief from unpleasant emotions after self-injury. ${ }^{31}$ Furthermore, among BPD patients, self-injury is associated with the reduction of dissociative symptoms (another diagnostic criterion for BPD). ${ }^{32,33}$

\section{Dissociation and Dissociative Disorders}

Dissociation is a clinical phenomenon in which an individual has the subjective perception of being psychologically, and in some cases physically, disengaged from reality. Dissociation symptoms are common among individuals with BPD and post- traumatic stress disorder. The available current research about dissociation and self-injury indicates that approximately $69 \%$ of individuals with dissociative disorders have a history of self-injury. ${ }^{10}$

\section{Eating Disorders}

Eating disorders include bulimia nervosa $(\mathrm{BN})$; anorexia nervosa, binge-purge subtype $(\mathrm{AN}-\mathrm{B} / \mathrm{P})$; and anorexia nervosa, restricting subtype (AN-R). Aggregated research suggests that self-injury is somewhat prevalent among people with eating disorders. Prevalence studies have found rates of self-injury ranging from $26 \%$ to $55 \%$ for those diagnosed with $\mathrm{BN}, 27 \%$ to $61 \%$ for those diagnosed with $\mathrm{AN}$ $\mathrm{B} / \mathrm{P}$, and $13 \%$ to $42 \%$ for those diagnosed with AN-R; both self-injury and eating disorders share similar correlates of risk for the behavior. ${ }^{34-40}$

\section{Major Depressive Disorder}

Only two studies to date has provided explicit data about self-injury and major depressive disorder (MDD). Nock et $\mathrm{al}^{41}$ found that $41.6 \%$ of adolescent inpatients who self-injure met criteria for MDD. Consistent with this finding, Nock and Kessler $^{22}$ found that $42 \%$ of their self-injuring sample (referred to by the researchers as "suicidal gesturers") aged 15 to 54 met criteria for MDD; $15.2 \%$ met criteria for dysthymic disorder. Although no research has yet examined self-injury prevalence among people who have been diagnosed with MDD or any other mood disorder, recent work by Jacobson et $\mathrm{al}^{42}$ found that the presence of a mood disorder predicted a history of self-injury.

\section{Alcohol Dependence}

Although much less research has examined selfinjury among substance-dependent patients, some research suggests that one-quarter to one-third may have histories of self-injury. ${ }^{22,43,44}$

\section{The Relationship between Self-Injury and Suicidal Behavior}

The relationship between self-injury and suicide is complex. There is evidence that a strong correlation between suicidality and self-injury exists. Empirical research indicates that as much as $40 \%$ of those who engage in self-injury have thoughts about suicide while inflicting the injury, ${ }^{1,45,46}$ and approximately $50 \%$ to $85 \%$ of people who injure themselves have attempted suicide at least once 
during their lifetime. ${ }^{47}$ Self-injurers who attempt suicide differ from their nonsuicidal counterparts in that these individuals tend to have longer histories of self-injury and tend to use more methods of self-injury. ${ }^{41,48}$ Recent research by Whitlock and colleagues $^{49}$ examining self-injury correlates in 2101 university students indicates that as the severity of self-injury accelerates, the severity of suicidality increases as well.

Self-injury and suicidal behavior are most easily differentiated by intent, method, and psychological impact. ${ }^{7,50}$ With respect to intent, self-injurers frequently report that the intention of the behavior is to reduce negative affect or emotion and not to cause death. ${ }^{1,31,51}$ The extant research in this area also indicates that people who engage in self-injury personally distinguish this behavior from attempted suicide. ${ }^{1,52,53}$ Moreover, a large proportion of those who self-injure do not think of killing themselves while they engage in self-injury, nor do they intend for the behavior to result in death. ${ }^{5,21}$

Empirical evidence suggests that there are a limited number of methods used in suicide attempts and completed suicides. Self-inflicted gunshots, hanging, overdose, self-poisoning, and jumping from lethal heights are attributed to approximately $87 \%$ to $98.6 \%$ of the deaths that result from suicide, whereas cutting accounts for only approximately $1.4 \%$ to $2 \%$ of these deaths. ${ }^{54-56}$ For nonfatal suicide attempts, prior research has found that drug overdoses are the most common method (68\% to $86 \%$ ), followed by cutting (9\% to $23 \%){ }^{54}$ In contrast, in both clinical and nonclinical populations cutting has consistently been shown to be the most common form of nonsuicidal self-injury, with approximately $70 \%$ of those who self-injure reporting that they have cut themselves. ${ }^{17,26,27}$

Nonetheless, the methods chosen for self-injury are likely to vary. Research has found that up to $69 \%$ of self-injurers use $\geq 2$ different methods of self-injury. ${ }^{45,49,50,57}$ Forms of self-injury most frequently reported besides cutting include burning, severe abrading/scratching of the skin, punching, biting, and inserting sharp objects under the skin. ${ }^{17,49}$ This variation may be because of a number of factors, including psychosocial circumstances (eg, living in a restricted residential treatment facility vs living at home), removal of access to preferred self-injury method, habituation to the sensation produced by each method, or personal preference. Alternatively, the number of methods used may reflect a subtype of self-injury, as suggested by latent class analyses forwarded by Klonsky and Olino ${ }^{45}$ and Whitlock et al. ${ }^{49}$

The psychological impact of self-injury also differentiates it from nonfatal suicide attempts. Selfinjury is typically associated with decreases in negative emotion and reports of increases in positive affect. ${ }^{26,27,51,58}$ Conversely, a nonlethal suicide attempt may precipitate worsened depressive symptoms and further suicidal behavior because of disappointment that death did not occur. ${ }^{59-61}$ Research indicates that up to $69 \%$ of those who attempt suicide report a previous suicide attempt. ${ }^{62}$ Nonetheless, nonsuicidal self-injury is more likely than suicidal behavior to be repeated and chronic. For example, Whitlock et $\mathrm{al}^{49}$ found that approximately one-quarter (23\%) of people reporting selfinjury also reported engaging in 11 to 50 separate episodes of self-injury, and another $9.9 \%$ reported $>50$ episodes of self-injury. It is possible that this is because self-injury may be easier to conceal than a suicide attempt, which may be more lethal. Another possibility is that self-injury is simply less damaging, although up to $55 \%$ of people who selfinjure report severe tissue damage. ${ }^{49}$

Finally, it is important to consider when selfinjury becomes a risk for suicide. Although there is a paucity of data in this area, some recent research by Muehlenkamp and Gutierrez ${ }^{15,63}$ indicates that people who self-injure are more likely to attempt suicide if they report being repulsed by life, are attracted to death, report not being afraid of suicide or death, are highly or chronically self-critical, exhibit apathy, or have tenuous family connections. Regarding this last factor, some research has also found that parental criticism is a predictor of both self-injury and suicide attempts as well as suicidal ideation. ${ }^{64}$ Thus, determining a patient's perspective on suicide or remaining alive can be an important part of identifying when self-injury is a potential risk for suicidal behavior.

\section{Self-Injury: Course and Outcome}

There is a dearth of information about the course of self-injury. Research has established that the typical age of onset for this behavior is between 14 and 24 years of age, with a bimodal peak in onset among people 12 to 14 and 18 to 19 years of age. ${ }^{65-68}$ Among adults with BPD, preliminary longitudinal research indicates that self-injury tends to 
cease over time for most individuals. Zanarini et $\mathrm{al}^{69}$ found that rates of self-injury in their sample of patients with BPD decreased from $80 \%$ to $28 \%$ during the course of 6 years. This same trend was seen among people with other personality disorders, for whom the rate of self-injury decreased from $16.7 \%$ to $1.6 \%$ during the same 6 -year period. Conversely, in a cross-sectional study of 43 inpatients with BPD and 40 non-BPD inpatients, Sansone and colleagues ${ }^{70}$ found that the mean number of types of self-injury steadily increased from childhood until the mid-20s, and then remained relatively stable through the sixth decade of life for both groups. Patients with BPD reported a significantly higher number of types of self-injury than patients without BPD from late childhood until the late 20s.

Both of the aforementioned studies examined select groups of participants (ie, patients with BPD, inpatients) who are not necessarily representative of people who self-injure as a whole. Although there is indeed a subset of people who chronically injure themselves, ${ }^{45}$ research by both Whitlock et $\mathrm{al}^{3,49}$ and Nock et $\mathrm{a}^{41}$ has found that the majority of people with any history of self-injury have selfinjured $<10$ times. Whitlock et al $^{49}$ found that those who self-injured $>10$ times were much more likely to produce greater damage with their selfinjury and to use more than 3 forms of self-injury; this suggests an overall greater severity and potentially more impairment for this subset. In aggregate, the existing data suggest that self-injury is most likely to occur only a few times, but the behavior may increase in frequency and severity when combined with other psychosocial factors, such as a psychiatric disorder or comorbid suicidality. Nonetheless, the available data pertaining to the long-term course of self-injury is quite limited at this time and reflects an area that requires substantially more research.

\section{Self-Injury in Primary Care Settings: The Role of Family Medicine Physicians}

Physicians in primary care and family medicine settings commonly have a trusting relationship with a patient that has developed over several years. In the best of circumstances this relationship involves a great deal of trust on the part of the patient. This kind of trust can take a long time to build with a behavioral health clinician who is new and unfamiliar to the patient. Thus, the physicianpatient relationship places the FM/PCP in a unique position to intervene and may serve as a valuable tool with regard to the assessment and management of self-injury.

People who self-injure, especially adolescents, are most likely to disclose their self-injury to family and friends first, particularly Internet-based acquaintances. ${ }^{66,71}$ Provided that the person has access to health care, primary care physicians are logically the next most likely person to discover the self-injurious behavior (eg, via physical examination, secondary to responding to a primary complaint resulting from the self-injury). Recent research by Fortune and colleagues ${ }^{72}$ suggests that a subset of those who experience urges to self-injure will actually seek help from a primary care physician as their first resource before self-injuring; a larger subset will seek help after self-injuring. In this situation, the physician has a unique role in helping the patient. A primary care physician's recommendation for either finding alternatives to selfinjury if the patient wants to (eg, exercise $)^{73}$ or seeking more intensive behavioral health treatment may be vital parts of assisting the self-injuring patient.

Although no empirical data on this topic exists, clinical experience and basic behavioral principles make it logical to conclude that patients may be more responsive to a trusted physician's concerns about self-injury. Furthermore, FM/PCPs are often in a unique position to be able to follow up with a patient for several years. In this way, these clinicians serve a vital role in monitoring the status of the patient's behavior, ensuring continuity of care and, if needed, reconnecting the patient with behavioral health services. The physician can also become familiar with the strategies the patient developed in therapy for coping with urges to selfinjure and can prompt the patient to consider, or reconsider, using those techniques that he/she has found helpful in the past should the self-injury reoccur.

Although some recommendations for therapists working with self-injurers have been published, ${ }^{6,7,74}$ no specific guidelines have been forwarded for working with self-injurers in nonpsychiatric settings. Nonetheless, the patientphysician relationship represents a valuable type of therapeutic relationship, and some of the same strategies recommended for use by psychothera- 
pists are likely to be useful for primary care physicians. These strategies (discussed below) include understanding a patient's self-injury and using validation strategies.

\section{Understanding Self-Injury}

It is important to note that FM/PCPs are unlikely to be able to provide the therapeutic services described later in this article because of the typically lengthy time required for implementing an evidence-based intervention for self-injury, and there remains a dearth of data for pharmacological interventions. Providing effective psychological interventions requires several years of training. However, one technique that can be used by primary care physicians is developing an understanding of the behavior. The questions needed to assess the behavior (discussed later in this article) can be extended to questions that may stimulate a process of change.

Motivational interviewing (MI) techniques ${ }^{75}$ provide a useful set of tools and structure for stimulating the change process while simultaneously assessing risk. As described by Kress and Hoff$\operatorname{man}^{76}$ in their work on the use of MI with selfinjurers, appropriately framed questions can be used as effective tools for eliciting the necessary information for risk assessment, thus allowing the practitioner to make referrals for appropriate services. More importantly, these types of inquiries can elicit a patient's commitment to getting treatment for their self-injury, making follow-through on referrals to behavioral health services more likely.

The following are examples of probing questions based on MI techniques that can (1) enhance a physician's understanding of self-injury from the patient's point of view, (2) facilitate enough discussion of self-injury to complete an adequate risk assessment, and (3) prompt a patient to begin thinking about getting help for his/her self-injury:

1. What effect is this having on your life?

2. It seems like self-injury serves a function for you. Are there any disadvantages to continuing to do this to yourself?

3. Is there anything that's motivating you to stop self-injuring right now?

4. It sounds like it's difficult to handle the stress in your life without self-injuring. How would your life be different right now if you were not selfinjuring?

5. There are a lot of options for getting help for this problem. What do you think you would need to help you stop self-injuring?

\section{Validation}

Inherent to understanding self-injury is the concept of validation. As noted by Nafisi and Stanley ${ }^{74}$ and Muehlenkamp, ${ }^{77}$ validation of a patient's feelings can foster a stronger patient-clinician relationship. For psychotherapists, this can mean greater progress in therapy. In a primary care context this can translate to greater adherence to medical advice and a higher probability of follow-through on referrals to behavioral health specialists.

Validation involves communicating your understanding of patients' experiences from their perspective and establishing that what the patient is expressing and feeling makes sense to you given the context in which it is being expressed. Validation also communicates to the patient that the clinician has heard them and has taken their experiences seriously enough to try to understand them. Accurate reflective listening is an essential validation strategy, particularly for patients reporting selfinjury. ${ }^{78}$ Reflective listening involves the clinician paraphrasing a patient's expressed thoughts and nonjudgmentally identifying his or her own observations about the nature of the patient's thoughts (eg, "It sounds like things have been really difficult for you and your girlfriend lately, and there are times when you're just not sure how to handle the stress."). Reflective listening also includes identifying emotions and the clinician summarizing the emotion that he or she hears the patient expressing (eg, "It sounds like you often feel angry right before you cut yourself.").

Complementing reflective listening is the validation skill of confirming a patient's thoughts, feelings, and behaviors within the context of current circumstances. This requires the physician to confirm the comprehensibility of a patient's emotions and actions in light of their situation (eg, "Considering what you are coping with right now, it makes sense that your anxiety would be so high, and it's difficult to know what to do with emotions that feel so intense."). Note that validation is not endorsement of a particular behavior or decision, but rather communicating that others in the exact same circumstances as the patient (ie, same stress level, 
Table 1. Risk/Severity Level by Number of Types and Episodes of Self-Injury

\begin{tabular}{lcl}
\hline Feature & Indicator & Severity/Risk \\
\hline Number of types used & 1 & Low \\
& $2-3$ & Moderate \\
& $>3$ & High \\
Number of episodes & $\leq 10$ & Low \\
& $11-50$ & Moderate \\
& $>50$ & High \\
\hline
\end{tabular}

same dilemma, same skills deficits, same family history) would probably make similar decisions. ${ }^{30,78}$ When attempting to help a self-injuring patient, communicating to them how "wrong" their behavior has been is likely to destroy communication and prevent them from seeking further help. Finally, articulating suspected unspoken thoughts or feelings is also validating for patients. This requires some knowledge and understanding of the patient and their history and involves making statements about what the patient's nonverbal behaviors are telling you (eg, "I notice that as we talk about this you look away. I imagine it's hard to admit that you hurt yourself to cope with stress.").

\section{Assessment of Self-Injury}

Although research focusing on self-injuring patients in primary care settings has been extremely limited, there is anecdotal evidence that family physicians are increasingly faced with the dilemma of providing some form of treatment to patients who engage in self-injury. As for any health care professional, it is important that FM/PCPs assess the risk level of their patients who self-injure.

There are 2 main considerations in evaluating risk. The first is evaluating the severity level of the patient's self-injury, which is based on the frequency of the behavior and the number of different methods used. ${ }^{6,7,44}$ In this regard, the preceding information regarding the course of self-injury can be synthesized into the risk categories depicted in Table 1, which are consistent with empirical evidence. ${ }^{7,48}$ Knowing the severity level of self-injury can be important to the second consideration of risk evaluation-the patient's risk of attempting suicide-because research has shown that as the severity of self-injury increases the risk for suicide also increases. ${ }^{47,79}$ Second, it is crucial to evaluate the risk that nonsuicidal self-injury will progress to suicide attempts. In evaluating these domains, considering the approximate frequency and the number of times the patient has engaged in self-injury is important. ${ }^{7}$ In this regard, the preceding information regarding the course of self-injury may be synthesized into the risk categories depicted in $\mathrm{Ta}$ ble $1{ }^{48}$ This risk categorization is consistent with empirical evidence.

\section{Instruments for Assessing Self-Injury}

A handful of instruments have been created to assess self-injury, including paper questionnaires and interview-style methods. Validated questionnaire assessments include the Deliberate SelfHarm Inventory, ${ }^{17}$ the Functional Assessment of Self-Mutilation, ${ }^{80}$ the Self-Harm Inventory, ${ }^{81}$ ) and the Self-Harm Behavior Questionnaire. ${ }^{82}$ Validated interview-style assessments include the Suicide Attempt Self-Injury Interview ${ }^{83}$ and the SelfInjurious Thoughts and Behaviors Interview. ${ }^{84,85}$ The Deliberate Self-Harm Inventory, the Functional Assessment of Self-Mutilation, the SelfHarm Behavior Questionnaire, and the Self-Injurious Thoughts and Behaviors Interview are available from the respective authors of the instruments (see references). The Suicide Attempt SelfInjury Interview is freely available online through the University of Washington Behavioral Research and Therapy Clinics website. ${ }^{86}$

Regardless of the instrument or method used for assessment, a thorough evaluation of the immediate harm that self-injury poses to the patient as well as the motivations for self-injury ${ }^{87}$ are essential for managing risk and determining the level of care to which the patient needs to be referred (eg, outpatient behavioral medicine consultation or acute inpatient care). Both Walsh ${ }^{6,7}$ and Claes and Vandereycken ${ }^{88}$ have outlined important guidelines for psychologists and psychiatrists to follow when conducting a thorough assessment of patients who selfinjure. However, most of these recommendations have been offered from the behavioral health care professional's perspective.

\section{Special Considerations for Primary Care Settings}

No guidelines for the assessment of self-injury presenting in primary care settings have been published to date. This is likely because of the nascent research literature regarding both the treatment and assessment of self-injury in primary care settings. Nonetheless, if a physician in a primary care 


\begin{tabular}{|c|c|c|}
\hline What to Assess & How to Assess It & $\begin{array}{c}\text { High-Risk Indicators Warranting Referral for } \\
\text { Behavioral Health Services }\end{array}$ \\
\hline Suicidal ideations & $\begin{array}{l}\text { "[Specific behavior] might be } \\
\text { different than trying to kill } \\
\text { yourself, but for some people } \\
\text { they're related. Do you ever } \\
\text { think about killing yourself when } \\
\text { you [specific behavior]? } \\
\text { - Do you think about killing } \\
\text { yourself when you don't [specific } \\
\text { behavior]?" }\end{array}$ & $\begin{array}{l}\text { - Intense thoughts about suicide while self-injuring } \\
\text { - Thoughts about suicide before or after self- } \\
\text { injuring }\end{array}$ \\
\hline Types & $\begin{array}{l}\text { - "What have you used to [specific } \\
\text { behavior]?" } \\
\text { "In what ways do you injure } \\
\text { yourself?" }\end{array}$ & $\begin{array}{l}\text { - Multiple types } \\
-\geq 3 \text { methods }\end{array}$ \\
\hline Onset & $\begin{array}{l}\text { "When did you first [specific } \\
\text { behavior]?" }\end{array}$ & $\begin{array}{l}\text { - Early/childhood onset } \\
\text { - Extended duration or history } \geq 6 \text { months }\end{array}$ \\
\hline Place/location & $\begin{array}{l}\text { "What parts of your body have } \\
\text { you [specific behavior]?" }\end{array}$ & $\begin{array}{l}\text { - Genitals or breasts } \\
\text { - Face }\end{array}$ \\
\hline Severity of damage & $\begin{array}{l}\text {-Has [specific behavior] ever } \\
\text { caused any bleeding/bruising/ } \\
\text { scarring?" } \\
\text { "Have you ever had to go to the } \\
\text { hospital after you [specific } \\
\text { behavior]?" } \\
\text { - "How do you handle the wound } \\
\text { after you [specific behavior]? }\end{array}$ & $\begin{array}{l}\text { - Hospitalization or suturing required } \\
\text { - Neglect of wounds } \\
\text { - Reopening of wounds }\end{array}$ \\
\hline Functions & $\begin{array}{l}\text { - "What does [specific behavior] } \\
\text { do for you?" } \\
\text { - "How do you usually feel before } \\
\text { [specific behavior]?" } \\
\text { "How do you usually feel after } \\
\text { [specific behavior]?" } \\
\text { "Would it help you in any way if } \\
\text { you stopped [specific behavior]?" }\end{array}$ & $\begin{array}{l}\text { - Any relationship to suicide (eg, compromise } \\
\text { between living and dying; reduces suicidal } \\
\text { thoughts or urges) }\end{array}$ \\
\hline Intensity of self-injury urges & $\begin{array}{l}\text { "How strongly would you rate } \\
\text { your urges to [specific behavior] } \\
\text { in a typical day from } 0 \text { to } 100 \text { ?" }\end{array}$ & - 70 or higher \\
\hline Repetition & $\begin{array}{l}\text { "About how many times would } \\
\text { you say you [specific behavior] } \\
\text { since you started?" }\end{array}$ & $\begin{array}{l}\bullet 11-50 \text { (moderate risk) } \\
\bullet \geq 50 \text { (high risk) }\end{array}$ \\
\hline Episodic frequency & $\begin{array}{l}\text { "How often do you [specific } \\
\text { behavior] in a typical day? What } \\
\text { about a typical week?" }\end{array}$ & $\begin{array}{l}\text { - Multiple times per week } \\
\text { - } \geq 5 \text { wounds per episode }\end{array}$ \\
\hline
\end{tabular}

setting encounters a patient who injures himself or herself, there is an onus of responsibility to facilitate that patient's care in the same way that the physician would facilitate the care of any other condition that requires more intensive clinical attention. As with other conditions, an adequate assessment is required to determine the most appropriate treatment or referral.

With the multitude of clinical data points that a primary care physician must synthesize, a routine structure for the assessment of self-injury can be useful. As noted earlier, identification of risk for escalation of the self-injury and for suicide is of most importance. This requires a practitioner to synthesize clinical data in a systematic way that indicates a patient's risk level. There are no specific standards of care yet published in the psychiatric literature regarding the data points essential to assess for when working with patients who engage in self-injury. However, based on the extant literature pertaining to nonsuicidal self-injury and its association to suicidal behavior and psychiatric morbidity, ${ }^{15,16,22,41,48}$ we suggest that the mnemonic device "STOPS FIRE" (see Table 2) may be used as a way of remembering what to look for when assessing a patient's self-injury:

- Suicidal ideations during or before self-injury

- Types of self-injury in which the patient engages 
- Onset of self-injury

- Place (location) on the body that is injured

- Severity and extent of damage caused by selfinjury

- Functions of the self-injury for the patient

- Intensity or frequency of self-injury urges

- Repetition of self-injury

- Episodic frequency of self-injury

It is important to note that the STOPS FIRE protocol above is not an empirically validated instrument; it is merely a mnemonic strategy for remembering the key domains to assess, in the same vein as "SIGECAPS" is not a validated tool but a strategy for remembering the domains to assess when evaluating depression. ${ }^{89}$ Table 2 provides some suggestions for basic probing questions that clinicians can use to acquire this information, as well as the indicators of higher risk that would warrant more intensive attention. We recommend the use of a conservative decision-making process for referring patients to behavioral health clinicians. Given the typical complexity of self-injury, referring patients with moderate risk indicators for outpatient services is appropriate. High-risk patients may warrant immediate inpatient services if they are an imminent danger to themselves or cannot commit to safety. At the very least these patients should be evaluated immediately by a behavioral health practitioner.

\section{Approaching the Assessment of Self-Injury Risk in Any Setting}

Self-injury may naturally elicit strong emotional responses from anyone, including health care professionals. Recommended practice guidelines for approaching a brief assessment of self-injury suggest that an effective evaluation should be approached using a nonjudgmental, dispassionate manner that blends interest in the patient with concern about helping them get treatment if they would like it. ${ }^{7}$ Qualitative data from those who self-injure indicates that questions should indicate a "respectful curiosity" about the behavior. ${ }^{90}$ Thus, any assessment needs to use a matter-of-fact line of inquiry. It is important that the patient feels that his or her distress has been heard and, ideally, understood by the clinician. ${ }^{74}$ However, this must be balanced with an effort not to reinforce the behavior by showing an excessive amount of concern. ${ }^{29}$ One option is to approach self-injury as one would approach any other clinical finding that would elicit a strong response. For example, emergency medicine physicians regularly encounter severe wounds and injuries that naturally produce emotional responses; FM/PCPs routinely encounter various infections that have been allowed to progress to advanced levels of pathology. In both of these situations, the natural emotional responses (eg, disgust, fear) must be contained in an effort to thoroughly evaluate the patient and provide him or her with appropriate care. Ignoring such a finding or reacting in a condescending manor would impede a physician's ability to provide the necessary evaluation and treatment. In short, demonstration of interest aimed at understanding the functions and severity of the self-injury, in the same way one would show interest in a wound or infection that a patient presents with, is likely to be the most productive approach in a primary care setting.

\section{Management and Treatment}

Identifying an effective treatment approach for self-injury can be a challenging aspect of working with people who engage in this behavior. Even after a treatment response is achieved, the positively and negatively reinforcing nature of this behavior often makes successful management of selfinjury complicated and challenging. Nonetheless, effective treatments do exist. This section describes the current existing therapies for self-injury and supporting data for those approaches. Data regarding treatments for self-injury are also summarized in Table 3.

\section{Pharmacologic Treatment}

At present there are no medications that are currently approved by the Food and Drug Administration for the specific treatment of self-injury. However, there is some limited data supporting specific pharmacological agents as potential treatments for self-injury in adults who are not developmentally delayed. ${ }^{91}$ Roth et $\mathrm{al}^{92}$ reported successful treatment of 7 female self-injurers with oral naltrexone. In this open-label trial, $50 \mathrm{mg}$ of naltrexone was administered daily. Complete abstinence from self-injury was observed in 6 of the 7 participants over a mean follow-up period of 10.7 weeks. Two participants resumed self-injuring when the medication was briefly stopped and then 


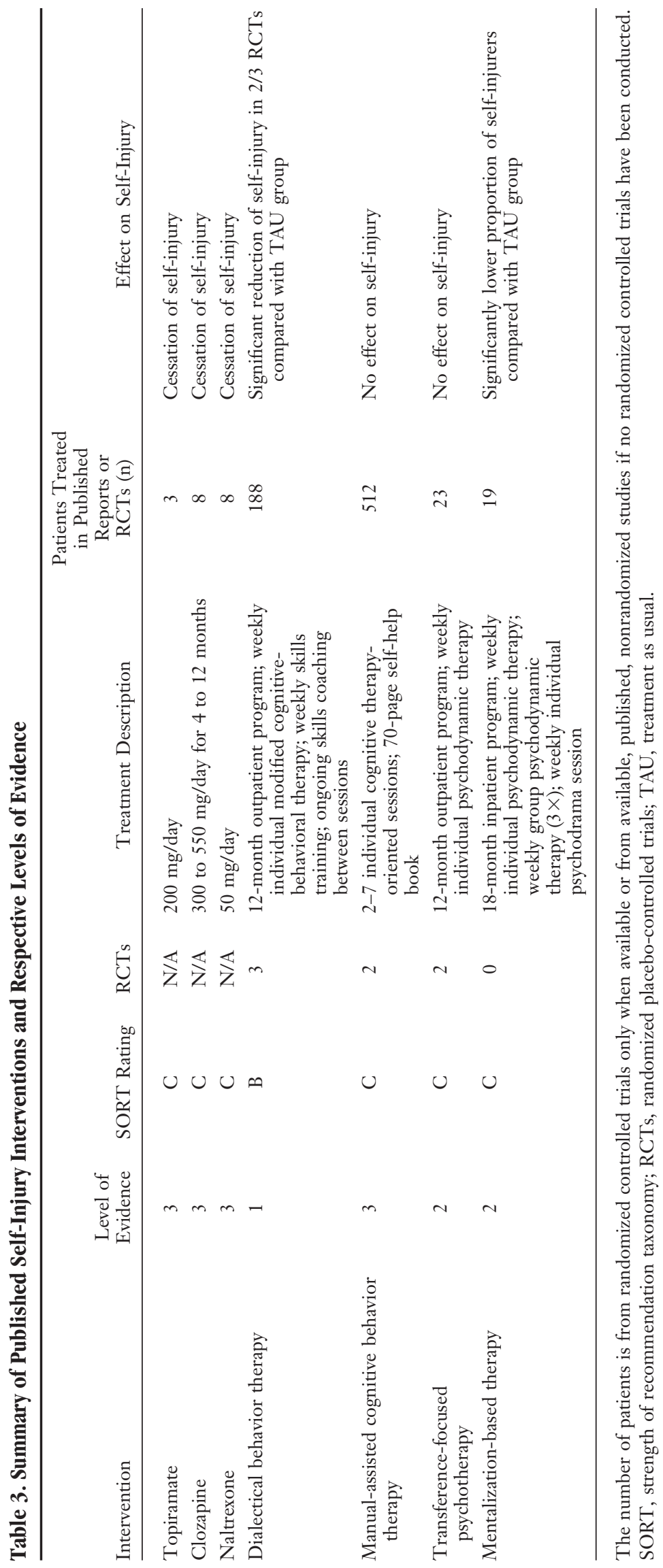


returned to abstinence when naltrexone therapy was resumed.

A similar finding was reported by Griengl et al. ${ }^{93}$ They reported successful resolution of self-injury with naltrexone $(50 \mathrm{mg} /$ day $)$ in a male patient for whom sertraline, doxepin, valproate, and risperidone had been unsuccessful. It is interesting to note the authors' observations that the patient's symptoms of depression were responsive to these other agents but the self-injury was not. After the start of naltrexone, the patient remained abstinent from self-injury during a 32-week follow-up period.

In addition to providing tentative support for naltrexone as a potential pharmacotherapy for selfinjury, the authors of both case reports described above suggest that these cases also support the endogenous opioid system model of chronic selfinjury. The endogenous opioid system model posits that self-injurers may have inherently low levels of opiate activity. ${ }^{94,95}$ In this model, self-injury serves as a mechanism for the release of additional endogenous opioids into the regions that are deficient in these substances. This restores the "opiatergic tone" (ie, a standard level of endogenous opiate activity, presumed to be inadequate in such individuals) to an adequate level. ${ }^{95}$ The underlying reward mechanism suggested for this model is the release of endorphins. Based on this model, opiate antagonists such as naltrexone would ostensibly block the positive reinforcement mechanism involved in self-injury.

Case-based support has also been found for clozapine as a treatment for self-injury. In a small $(\mathrm{n}=$ 7) archival study of self-injuring, psychotic, female inpatients with BPD, Chengappa et $\mathrm{al}^{96}$ found that clozapine was successful in reducing self-injury after previous trials of myriad selective serotonin reuptake inhibitors, neuroleptics, and atypical antipsychotics had been unsuccessful. Despite a very small sample, Chengappa et al ${ }^{96}$ reported statistically significant decreases in episodes of self-injury after the start of clozapine therapy. In addition, self-injury ceased completely in 3 of the 7 patients. For all patients, daily clozapine dosages ranged from 300 to $550 \mathrm{mg}$, and treatment length ranged from 4 to 12 months. Ferreri et $\mathrm{al}^{97}$ reported successful resolution of chronic self-injury in a female patient with BPD during a follow-up period of 4 weeks with clozapine that was titrated up to a maximum dosage of $300 \mathrm{mg} /$ day.
In addition, 2 reports have provided preliminary evidence for the use of topiramate for the treatment of self-injury. In their study of topiramate as an adjunctive treatment for manic symptoms in bipolar disorder, Chengappa et $\mathrm{al}^{98}$ reported an ancillary finding that 2 participants with comorbid bipolar disorder I and BPD who exhibited manic symptoms and self-injury stopped injuring themselves after commencement of topiramate (the dosage was unspecified). Similarly, Cassano et $\mathrm{al}^{99}$ also reported that topiramate $(200 \mathrm{mg} /$ day $)$ produced cessation of self-injury in a patient with BPD and bipolar disorder II when added as an adjunctive therapy for mood stabilization.

The data presented regarding pharmacological treatment of self-injury is preliminary evidence at best. In most cases, the pharmacological agents were added or started after the failure to obtain a treatment response with several other medications. Although there may be some reasonable hypotheses about why these medications could or should be effective in reducing self-injury (eg, naltrexone is an opiate antagonist), the case descriptions clearly suggest that they were essentially "a shot in the dark" for treating treatment-refractory patients. $\mathrm{Al}$ though these data represent potentially promising starting points for systematic clinical studies, the strength of the current evidence is not conducive to recommending these agents for the treatment of self-injury. Randomized, placebo-controlled trials would be required to establish the efficacy, safety, and action mechanisms of these agents for the treatment of self-injury. Thus the current strength of recommendation taxonomy (SORT) level of evidence rating for all pharmacological interventions for self-injury is 3 and SORT recommendation rating is $\mathrm{C}$.

\section{Psychosocial Interventions}

To date there are no known empirical trials of treatments specifically addressing nonsuicidal selfinjury. Treatments that do address this behavior have historically done so in the context of concomitant suicidal behaviors or other related forms of psychopathology (eg, BPD). Therefore, the treatments discussed in this section are specific to BPD. Data from trials of these therapies pertaining to their effects on self-injury are highlighted. Although a detailed description of the theoretical basis for all treatments is beyond the scope of this 
manuscript, a basic description of each treatment is provided below, followed by outcome data.

\section{Psychodynamic Psychotherapies}

Transference-Focused Psychotherapy. Transferencefocused psychotherapy (TFP) was developed as an intensive treatment for patients with BPD. ${ }^{100}$ This treatment shares the common goals of all BPD treatments: reduction of suicidal behavior, self-injury, and interpersonal chaos; and improvement of affective regulation and behavioral control.

In general terms, TFP aims to help patients change their affective and behavioral responses to stress, especially in interpersonal contexts, by providing extensive opportunities for discussion of the patient-therapist relationship during regular therapy sessions twice per week for 1 year. This relationship is conceptualized as both a microcosmic representation of how the patient approaches other relationships in his or her life and as a "holding environment" in which the patient can safely express themselves without fear of losing the therapist (unless they violate the treatment contract established at the beginning of treatment). Through intensive focus on the therapy relationship as a primary content of sessions, the patient can learn new understandings of and responses to interpersonal relationships, as well as the necessary affective and behavioral control techniques required for fostering healthier interpersonal relationships. ${ }^{101,102}$

Thus far, TFP has shown some promise as a psychosocial treatment for self-injury, but more so for BPD as a whole. An initial effectiveness study ${ }^{103}$ of 23 outpatients with BPD found that the severity of self-injury and the level of medical care required after self-injury were reduced after 1 year of TFP. However, the frequency of self-injury was not significantly changed $(P=.45)$. Subsequent randomized clinical trials of the efficacy of TFP ${ }^{104,105}$ compared this treatment to dialectical behavior therapy $(\mathrm{DBT})^{29}$ and an active placebo. Levy et $\mathrm{al}^{104}$ reported data pertaining to changes in "attachment patterns" and "reflective function" (both TFP-related constructs), but failed to discuss the effect of TFP on self-injury. Similarly, Clarkin et $\mathrm{al}^{105}$ reported improvements in impulsivity, social functioning, depression, anxiety, and suicidality in their controlled trial (finding treatment equivalence between DBT and TFP on this latter variable), but no data on self-injury was reported.
It is logical to conclude (and proponents of TFP contend) that a treatment that treats the crux of a psychopathology will result in changes to the myriad manifestations of that psychopathology, such as self-injury. However, as it pertains to self-injury specifically, the data about TFP published to date are relatively weak. Moreover, Clarkin et al's ${ }^{103}$ original findings of the potential effects of TFP in reducing the severity of self-injury have not been replicated in (or at least have not been reported in) subsequent trials. Currently, the data supporting TFP as a treatment for self-injury is level 2 evidence and SORT recommendation rating of $\mathrm{C}$ for the use of (or referral for) this treatment, owing primarily to a lack of replication (or, at least, a lack of publication) of findings about the effectiveness of TFP for reducing self-injury. Further research on this treatment is needed to determine its effectiveness in modifying self-injury.

Mentalization-Based Therapy. Mentalization-based therapy (MBT) is another treatment for BPD that is derived from psychodynamic attachment theory. ${ }^{106}$ This therapy was originally developed by Bateman and Fonagy ${ }^{106}$ as part of a day treatment program for severely and chronically dysfunctional patients with BPD. The general theoretical premise of MBT is that BPD results from a patient's lack of awareness of the relationships between thoughts and emotions, which adversely impacts interpersonal attachments. MBT is aimed at increasing the patient's ability to "mentalize," that is, to focus attention on and understand thoughts and emotions in an attempt to more accurately interpret one's own and others' behavior, thereby improving interpersonal functioning. ${ }^{106,107}$ This is accomplished through an intensive 18-month partial hospitalization program with a weekly treatment program consisting of a 1-hour individual psychoanalytic psychotherapy session; 3, 1-hour group analytic psychotherapy sessions; a 1-hour psychotherapy session aimed at teaching psychodrama techniques; a 1-hour weekly "community meeting"; a monthly meeting with a case worker; and a monthly medication management meeting with a psychiatrist.

The initial effectiveness study ${ }^{107}$ was a nonrandomized trial comparing MBT (administered by psychiatric nurses and supervised by clinical psychologists) to general milieu psychiatric treatment (treatment-as-usual [TAU]) for 19 patients with BPD. Bateman and Fonagy ${ }^{98}$ reported significantly fewer episodes of self-injury and suicide attempts in the MBT group than the TAU group at the 12- 
month assessment, and a significantly lower proportion of self-injuring patients in the MBT group than the TAU group was observed at the 18-month assessment despite no significant differences in proportions at baseline. ${ }^{106} \mathrm{~A}$ subsequent 8 -year follow-up study ${ }^{108}$ found significantly fewer suicide attempts in the MBT group versus the TAU group, among other maintained improvements (eg, psychosocial functioning, days in the hospital). However, no data about self-injury was presented by the authors for this follow-up.

Similar to TFP, the data pertaining to the effectiveness of MBT in treating self-injury is promising. However, the data for MBT as a treatment for self-injury remains as level 2 evidence at best. This is largely because of a lack of an active treatment comparison group, a lack of randomization, and a lack of replication thus far. Furthermore, although potential mechanisms of change in MBT have been articulated, ${ }^{107}$ the setting in which MBT was conducted (a partial hospitalization program) also provided for a multitude of other therapeutic interactions. It may be reasonably argued that 18 months of structured, intensive therapeutic contact (5 hours per week in the case of MBT) in a partial hospitalization program of any kind may yield similar effects. Therefore, the active component of MBT that produces change remains unclear. When considering the outcome data for MBT, the evidence for this therapy as an intervention for selfinjury is level 3, with a SORT recommendation rating of C.

\section{Cognitive and Cognitive-Behavioral Psychotherapies}

Manual Assisted Cognitive-Behavioral Therapy. Manual assisted cognitive behavioral therapy $(\mathrm{MACT})^{109}$ was developed as a brief, cost-effective intervention for the reduction of self-injury in patients with a history of repeated self-injurious behaviors. This treatment combines 2 to 6 sessions of individual cognitive-behavioral and solution-focused psychotherapy with self-directed bibliotherapy. The bibliotherapy component employs 6 short book chapters that focus on teaching patients emotion management skills, ways to cope with negative thought patterns, and skills to prevent relapse into self-injury. Both therapy sessions and bibliotherapy components focus on problem solving. This is accomplished in part by helping the patient understand the origins and triggers for their self-injury through use of a behavioral chain analysis form, as well as via thought and behavior monitoring forms.

Evans et al. ${ }^{109}$ compared MACT to a TAU condition in a randomized controlled pilot trial that included 32 patients who were habitually self-injuring. Results indicated that the MACT group had lower monthly rates of self-injury and longer times until the next episode of self-injury than the TAU group, but neither of these differences reached statistical significance. A larger randomized controlled trial $^{110}$ compared MACT to a TAU condition in 480 outpatients. Patients receiving MACT had up to 7 sessions of individual, solution-focused therapy along with a 6-chapter, 70-page book (described above). Results of this larger trial revealed that MACT was not associated with a significantly greater reduction in self-injury at either 6- or 12month assessment than was TAU, and that MACT was not associated with a significant change in self-injury from pre- to posttreatment assessment. Nonetheless, a nonsignificantly smaller proportion of MACT participants (39\%) than TAU participants $(46 \%)$ reported ongoing self-injury at the 12 -month assessment. In addition, survival analyses revealed that MACT participants went for a longer period of time (222 days) than TAU participants (169 days) before their repeat episode of self-injury, although this difference was also not statistically significant. Similar to the study by Evans et al, ${ }^{109}$ this second trial ${ }^{110}$ was also characterized by substantial heterogeneity in the way treatment actually occurred within each group, which may account for a lack of group differences. For example, 5 MACT participants reported that they never received a booklet, and 90 participants (almost 40\%) never attended an individual psychotherapy session. Likewise, TAU included individual problem-solving therapy, seeing a general practitioner for treatment, group therapy, psychodynamic psychotherapy, or brief counseling. Thus, the failure to find any differences between groups is perhaps not surprising because the design and execution of the study was not conducive to comparing the effects of discrete treatment conditions on a unitary outcome measure. Both Tryer et $\mathrm{al}^{110}$ and Evans et $\mathrm{al}^{109}$ note the cost-effectiveness of MACT as a brief treatment. However, the extant data do not support this as a rationale for recommending MACT as an intervention for self-injury given the nonsignificant differences noted between MACT and TAU groups. Additional research is needed to more rig- 
orously evaluate this treatment and further refine the treatment components.

Dialectical Behavior Therapy. DBT ${ }^{30}$ was developed as a cognitive-behavioral treatment for chronically suicidal and self-injuring patients diagnosed with BPD. DBT is considered to be an acceptancebased treatment because of its focus on both developing patients' self-acceptance and its strategic utilization of an accepting and nonjudgmental stance by the therapist. DBT is based on Linehan's ${ }^{30}$ biosocial model of BPD. This model postulates that $\mathrm{BPD}$ is a pervasive disorder of the emotion regulation system, which develops as a result of a transactional relationship between caustic and abusive conditions in one's developmental environment and a genetic predisposition toward rapid and frequent fluctuations between emotional extremities and intensities. ${ }^{111-115}$ Thus, this model conceptualizes self-injury as a maladaptive emotional regulation strategy that originates from deficits in emotion regulation skills. ${ }^{30}$ DBT is a comprehensive cognitive-behavioral treatment that is designed to address these skills deficits as a way of reducing suicidality and self-injury among people with BPD.

There are 4 modes of treatment involved in standard, adult DBT: (1) 12 months of weekly individual therapy; (2) 12 months of weekly group psychosocial skills training; (3) skills coaching and consultation to patients between sessions; and (4) the therapist's participation in a consultation team. The 4 modes of treatment are structured around the 4 stages of treatment: (1) learning to control uncontrolled behaviors; (2) increasing awareness and experience of emotions; (3) decreasing general problems with life; and (4) increasing quality of life. Patients who enter a DBT program commit to 1 year of treatment and to working toward the goal of reducing all self-injurious behaviors (including suicidal behaviors) as the primary goal of treatment. Secondarily, patients agree to address any behaviors that are obstacles to the first goal. In this way, behaviors that sabotage treatment are reduced and the potential for therapy to be effective is increased. Group psychosocial skills training also takes place weekly and serves as a required didactic supplement to the weekly individual therapy session. ${ }^{30,116}$ Through skills training, patients develop and learn how to apply skills in 4 domains: (1) emotional regulation, (2) distress tolerance, (3) interpersonal effectiveness, and (4) self-awareness ("mindfulness") skills. ${ }^{116}$
DBT was first evaluated by Linehan and her colleagues ${ }^{117}$ in a randomized, controlled trial that compared DBT $(\mathrm{n}=24)$ to a TAU $(\mathrm{n}=23)$ condition. This initial effectiveness study randomly assigned female patients with BPD and a history of at least 2 suicide attempts or 2 episodes of selfinjury during the past year to either 1 year of DBT or 1 year of treatment by a mental health service provider in the community. DBT patients received the treatment package described above, whereas the TAU patients received a diverse array of other treatments that may or may not have included individual therapy sessions. Initial results revealed that patients who received DBT had significantly fewer episodes of self-injury at each 4-month assessment interval point, including posttreatment. In addition, during the course of the 1-year followup, ${ }^{118}$ DBT patients were significantly less likely to resume self-injurious behavior during the first 6 months than were the TAU patients $(26 \%$ vs $60 \%$, respectively). However, this difference was not significant at the 12-month follow-up assessment.

Koons et $\mathrm{al}^{119}$ evaluated the effectiveness of DBT for female veterans diagnosed with BPD ( $\mathrm{n}=$ 10) compared with a weekly 1 -hour therapy TAU condition $(\mathrm{n}=10)$. Analyses combined suicide attempts and nonsuicidal self-injury, making specificity of treatment effects hard to identify. Nonetheless, this study revealed a significant decrease in aggregated self-harming behaviors across all 3 assessment periods for patients with DBT $(P=.04)$ but not for TAU patients $(P=.98)$, as well as a trend for differences in self-harm episodes before and after treatment for patients receiving DBT $(P=.06)$ but not for TAU patients $(P=.25)$. Additionally, a trend toward significance $(P=.07)$ was found for the between-group differences in the proportions of participants reporting self-harming behaviors; the proportion of patients reporting any self-harming behaviors decreased from $50 \%$ to $10 \%$ for patients with DBT versus $30 \%$ to $20 \%$ for TAU patients.

In a more recent randomized, controlled trial among patients receiving DBT, Linehan et $\mathrm{al}^{120}$ randomly assigned female patients with $\mathrm{BPD}$ to 1 year of either DBT $(n=52)$ or community treatment by experts $(n=49)$. Community treatment by experts consisted of individual therapy by 25 therapists who identified the treatment they provided to patients as either "nonbehavioral" or "psychodynamic." Results of this trial indicated significantly 
lower rates of self-injury at posttreatment for patients receiving DBT but no significant differences between groups. Thus, DBT was equally as effective at reducing self-injury as nonbehavioral treatment by experts. However, during the course of this 2-year trial, patients receiving DBT had significantly lower mean medical severity across all self-harming (self-injurious and suicidal) behaviors and significantly fewer suicide attempts than did the TAU participants.

DBT has also been adapted, modified, and evaluated for inpatient and adolescent populations. Thus far, no randomized controlled trials have been conducted; however, evidence with lower strength is available. Barley and colleagues ${ }^{121}$ reported the effects of integrating skills training onto an inpatient personality disorders unit. This study evaluated, among other variables, self-injury outcomes in 130 patients admitted to an inpatient facility. Compared with self-injury data from the general psychiatry inpatient unit in the same hospital, patients on the personality disorders unit evidenced significantly fewer episodes of self-injury after DBT was implemented. More recently, Bohus et $\mathrm{al}^{122}$ adapted DBT for an inpatient setting. The treatment used a standard DBT protocol of individual therapy, skills training, and skills coaching fitted into a 4-week program. In their evaluation of the effectiveness of 24 female inpatients diagnosed with BPD and who reported a history of at least 2 episodes of self-injury during the last 2 years, DBT was effective in significantly reducing the frequency of self-injury $(P=.004)$. That 19 of the 24 inpatients were medication-free throughout the latter study is a noteworthy consideration.

Finally, Rathus, Miller, and colleagues, ${ }^{123-125}$ and Katz and colleagues ${ }^{126}$ have adapted DBT for adolescent populations. Rathus et $\mathrm{al}^{125}$ originally adapted DBT by reducing treatment length to 12 weeks, reducing the skills taught, and including the family in skills training. In a quasi-experimental effectiveness study, Rathus and Miller ${ }^{123}$ found that, among suicidal adolescent outpatients with BPD features, the group receiving DBT $(\mathrm{n}=29)$ had significantly fewer hospitalizations during treatment than a TAU group $(\mathrm{n}=82)$, and there were no significant differences in suicide attempts between groups. However, there was a significant decrease in suicidal ideations in the DBT group at posttreatment. No data about self-injury specifically was reported. Katz et $\mathrm{al}^{126}$ adapted inpatient
DBT for adolescents, implementing a 2-week program that consisted of daily skills training and individual DBT. Results of a quasi-experimental study found that this adaptation of DBT significantly reduced self-harm behavior in aggregate, including self-injury, during a 1-year follow-up period. In addition, significant reductions in suicidal ideations were found at discharge and 1-year follow-up.

DBT has been subjected to more scrutiny than any other treatment for self-injury. However, the data about the actual effectiveness of DBT are mixed and suggest a modest effect of this treatment on self-injury. In aggregate, the literature indicates that DBT is likely to reduce self-injury (as well as risk of suicide attempts) during the course of treatment and that these effects are likely to last for up to 6 months without further treatment and for $\geq 1$ year with further intermittent treatment contact. ${ }^{117-120}$ Based on the quality of research about DBT, the evidence for DBT as an intervention for self-injury is level 1; however, the SORT recommendation rating for DBT is $\mathrm{B}$ because of the inconsistency of demonstrated effects on this behavior specifically.

The studies discussed above were generally welldesigned randomized, controlled trials. However, there are some notable shortcomings of DBT research. First, compared with other treatments, DBT has only been systematically evaluated in women. This is a substantial limitation of the generalizability of DBT to the populations it purports to treat. Although approximately $75 \%$ of individuals with BDP are women, the DBT literature says nothing about its effectiveness with the remaining $25 \%$ that consists of men.

Second, from a design perspective, research about DBT is limited by a lack of comparison with specific alternative treatments. Thus far, research about DBT has used poorly defined TAU conditions. The original studies ${ }^{117,118}$ compared DBT to a condition in which patients received an indeterminate level of therapeutic contact. Perhaps any patient with BPD who receives 3 hours of structured, goal-directed contact weekly would improve to a greater degree than would patients who may only receive 30 or 60 minutes of group or individual treatment. Although the degree of change evidenced in this first trial was significant, the most recent trial of $\mathrm{DBT}^{120}$ did not find significant between-group differences for self-injury. The com- 
parison condition was slightly better defined (and ostensibly consisted of greater expertise) in this latest study, but it was still lacking a clear description of the alternative treatment.

Another problem with DBT, as with other treatments, is an inadequate or inconsistent definition of outcome measures for self-harm behaviors. The use of the term "parasuicide" by Linehan, ${ }^{30}$ Linehan et al, ${ }^{117}$ and many others has contributed to this definitional problem. In Koons and colleagues ${ }^{119}$ study, for example, there were notable decreases in aggregated self-harm behaviors, but these behaviors included both suicidal and nonsuicidal self-injury. In Linehan et al's ${ }^{120}$ recent clinical trial, medical severity of self-harm behaviors was examined across types of self-harm.

The data from the DBT literature are promising and clearly suggest treatment effects. Thus far these data give more hope for suicide prevention and self-injury reduction than any other treatment. However, the current data leave us with unanswered questions: For whom is DBT best suited (eg, only white women)? What is DBT best suited for treating? and To which treatments is DBT a superior intervention? Research on DBT could be greatly enhanced by including well-defined comparison treatments. Finally, one oft-cited concern about DBT is the considerable startup cost involved in implementing a program because of the extensive training required. ${ }^{119}$ Although modified approaches have been found to be at least somewhat effective, ${ }^{122-127}$ DBT is still typically viewed as a necessarily comprehensive treatment approach for a complex clinical problem (ie, BPD).

\section{Summary of Treatment Data}

Hundreds of patients have now been treated in clinical trials of interventions that address self-injury (see Table 3 for a summary of findings). Although some research and analyses have been more sound than others, the research evaluating all the known interventions has shortcomings. Across all clinical trials and all treatment modalities for selfinjury interventions, it seems that one common theme among effective therapies is consistent therapeutic contact during a relatively long-term course of treatment. TFP, MBT, and DBT all require generally intensive contact with a treatment provider during a longer period of time than do standard short-term treatments (eg, 16 to 20 weeks of CBT for depression). Another common theme is the acquisition of new skills during treatment. Regardless of the terminology or theory used, the effectiveness of TFP, MBT, and DBT (ie, the effective treatments) is contingent on a patient's ability to learn how to do things differently. Whether learning how to relate to or interact with others more assertively, how to take care of themselves more consistently, or how to tolerate distress more effectively, patients receiving all of these treatments are required to learn, develop, and apply new skills to get better. It is possible that an intervention based on a transtheoretical model would prove to be a more efficacious treatment than the current extant therapies. Future research may be best directed toward identifying the active components in each of these treatment approaches to determine the most effective and comprehensive package.

\section{Conclusions}

Self-injury is a serious behavioral problem that may be increasing in prevalence. ${ }^{40}$ Trends identified by research point toward the probability that, in the near future, FM/PCPs are likely to see patients who self-injure more frequently. These patients present a higher safety risk than does the typical clinic patient. Nonetheless, effective evaluation of self-injury can be completed rapidly using the protocol provided and is essential to effective risk management and referral to appropriate psychosocial and behavioral therapies.

As noted by Lofthouse and Yaeger-Schweller, ${ }^{128}$ behavioral health care providers are typically best equipped to treat the self-injurer from a long-term perspective, and it is advisable for the FM/PCP to make an appropriate referral. Nonetheless, treatment of self-injury among primary care patients begins with an effective patient-physician relationship. FM/PCPs have a unique opportunity to monitor the patient over a longer period of time than might a psychotherapist. This may allow for better follow-up on the patient's part and stronger reinforcement of any new skills learned in therapy.

Effective psychotherapeutic treatments are available for patients who self-injure. Regardless of the type of psychotherapy used, all treatments seem to share the common thread of addressing underlying psychological dysfunction and skill deficits. The key to management of self-injury is getting the patient connected with the appropriate behavioral health services. 
Risk assessment of patients who self-injure is also critical. A first step in this direction is identifying patients who self-injure. Considering regular screening of patients at a higher risk has been recommended and may be an important consideration for FM/ PCPs. ${ }^{128}$ The tools discussed in this article are wellsuited for this purpose. Once self-injury is detected, assessment of the patient's risk level is the next important step. The mnemonic "STOPS FIRE" can be used for remembering key factors of self-injury that must be assessed; the data discussed here can be synthesized to determine a patient's risk for repetitive self-injury and/or suicidal behavior.

As an FM/PCP, monitoring one's own response to a patient's self-injury so as to neither reinforce nor ignore this behavior is likely to facilitate better quality information on which to base risk-management decisions. Validation and understanding of the patient's self-injurious behavior serve as valuable tools both for tempering an emotional response and for eliciting important information from a patient who self-injures. In this way, the FM/PCP can uniquely facilitate a more seamless treatment process for the patient-beginning with their office visit - to ensure that the patient receives the services they need.

\section{References}

1. Favazza AR. Bodies under siege: self-mutilation and body modification in culture and psychiatry, 2nd ed. London: Johns Hopkins; 1996.

2. Olfson M, Gameroff MJ, Marcus SC, Greenberg T, Shaffer D. National trends in hospitalization of youth with intentional self-inflicted injuries. Am J Psychiatry 2005;162:1328-35.

3. Whitlock J, Eckenrode J, Silverman D. Self-injurious behaviors in a college population. Pediatrics 2006;117:1939-48.

4. Regier DA, Narrow WE, Rae DS, Manderschied RW, Locke BZ, Goodwin FK. The de facto US mental and addictive disorders service system: epidemiological catchment area prospective 1-year prevalence rates of disorders and services. Arch Gen Psychiatry 1993;50:85-94.

5. Simeon D, Favazza AR. Self-injurious behaviors: phenomenology and assessment. In Simeon D, Hollander E, eds. Self-injurious behaviors: assessment and treatment. Washington, D.C.: American Psychiatric Publishing; 2001.

6. Walsh BW. Treating self-injury: a practical guide. New York: Guilford Press; 2006.

7. Walsh B. Clinical assessment of self-injury: a practical guide. J Clin Psychol 2007;63:1057-66.

8. Huband N, Tantam D. Attitudes to self-injury within a group of mental health staff. $\mathrm{Br} \mathrm{J}$ Med Psychol 2000;73:495-504.

9. McAllister M, Creedy D, Moyle W, Farrugia C. Nurses' attitudes towards clients who self-harm. J Adv Nurs 2002;40:578-86.

10. Briere J, Gil E. Self-mutilation in clinical and general population samples: prevalence, correlates, and functions. Am J Orthopsychiatry 1998;68:609-20.

11. Klonsky ED, Oltmanns TF, Turkheimer E. Deliberate self-harm in a nonclinical population: prevalence and psychological correlates. Am J Psychiatry 2003;160:1501-8.

12. Hawton K, Rodham K, Evans E. By their own young hand: deliberate self-harm and suicidal ideas in adolescents. London: Jessica Kingsley Publishers; 2006.

13. Laye-Gindhu A, Schonert-Reichl KA. Nonsuicidal self-harm among community adolescents: understanding the "whats" and "whys" or self-harm. J Youth Adolesc 2005;34:447-57.

14. Lloyd-Richardson EE, Perrine N, Dierker L, Kelley ML. Characteristics and functions of nonsuicidal self-injury in a community sample of adolescents. Psychol Med 2007;37:1183-92.

15. Muehlenkamp JJ, Gutierrez PM. Risk for suicide attempts among adolescents who engage in nonsuicidal self-injury. Arch Suicide Res 2007;11:6982.

16. Plener P, Libal G, Keller F, Fegert JM, Muehlenkamp JJ. An international comparison of adolescent non-suicidal self-injury (NSSI) and suicide attempts: Germany and the USA. Psychol Med 2009; 39:1549-58.

17. Gratz KL. Measurement of deliberate self-harm: preliminary data on the Deliberate Self-Harm Inventory. J Psychopathol Behav Assess 2001;23:25363.

18. Weiderman MW, Sansone R, Sansone LA. Bodily self-harm and its relationship to childhood abuse among women in a primary care setting. Violence Against Women 1999;5:155-63.

19. Claes L, Vandereycken W, Vertommen H. Selfinjury in female versus male psychiatric patients: a comparison of characteristics, psychopathology and aggression regulation. Pers Individ Dif 2007;42: 611-21.

20. Kessler RC, Borges G, Walters EE. Prevalence of and risk factors for lifetime suicide attempts in the National Comorbidity Survey. Arch Gen Psychiatry 1999;56:617-26.

21. Favazza AR. The coming of age of self-mutilation. J Nerv Ment Dis 1998;186:259-68.

22. Nock MK, Kessler RC. Prevalence of and risk factors for suicide attempts versus suicide gestures: analysis of the National Comorbidity Survey. J Abnorm Psychol 2006;115:616-23.

23. Darche MA. Psychological factors differentiating 
self-mutilating and non-self-mutilating adolescent inpatient females. Psychiatr Hosp1990;21:31-5.

24. Hurry J. Deliberate self-harm in children and adults. Int Rev Psychiatry 2000;12:31-6.

25. Lofthouse N, Muehlenkamp J, Adler R. Non-suicidal self-injury and co-occurrence. In Nixon MK, Heath NL, eds. Self-injury in youth: the essential guide to assessment and treatment. New York: Routledge Press; 2008:59-78.

26. Nock MK, Prinstein MJ. A functional approach to the assessment of self-mutilative behavior. J Consult Clin Psychol 2004;72:885-90.

27. Nock MK, Prinstein MJ. Contextual features and behavioral functions of self-mutilation among adolescents. J Abnorm Psychol 2005;114:140-6.

28. Clarkin JF, Widiger T, Frances A, Hurt SW, Gilmore M. Prototypic typology and the borderline personality disorder. J Abnorm Psychol 1983;92:263-75.

29. Cowdry RW, Pickar D, Davies R. Symptoms and EEG findings in the borderline syndrome. Int J Psychiatry Med 1985;15:201-11.

30. Linehan MM. Cognitive-behavioral treatment of borderline personality disorder. New York: Guilford Press; 1993.

31. Brown MZ, Comtois KA, Linehan MM. Reasons for suicide attempts and nonsuicidal self-injury in women with borderline personality disorder. J Abnorm Psychol 2002;111:198-202.

32. Briere J. Child abuse trauma theory and treatment of the lasting effects Newbury Park, CA: Sage Publications; 1992.

33. Kemperman I, Russ MJ, Shearin E. Self-injurious behavior in borderline patients. J Pers Disord 1997; 11:146-57.

34. Claes L, Vandereycken W, Vertommen H. Selfinjurious behaviors in eating disorder patients. Eat Behav 2001;2:262-72.

35. Claes L, Vandereycken W, Vertommen H. Eating disordered patients with and without self-injurious behaviours: a comparison of psychopathological features. Eur Eat Disord Rev 2003;11:379-96.

36. Mitchell JE, Boutacoff LI, Hatsukami D, Pyle RL, Eckert ED. Laxative abuse as a variant of bulimia. J Nerv Ment Dis 1986;174:174-6.

37. Paul T, Schroeter K, Dahme B, Nutzinger DO. Self-injurious behavior in women with eating disorders. Am J Psychiatry 2002;159:408-11.

38. Welch SL, Fairburn CG. Impulsivity or comorbidity in bulimia nervosa: a controlled study of deliberate self-harm and alcohol misuse in a community sample. Br J Psychiatry 1996;169:451-8.

39. Favaro A, Santonastaso P. Self-injurious behavior in anorexia nervosa. J Nerv Ment Dis 2000;188: $537-42$.

40. Weiderman MW, Pryor T. Substance use and impulsive behaviors among adolescents with eating disorders. Addict Behav 1996;21:269-72.
41. Nock MK, Joiner TE, Gordon KH, Lloyd-Richardson E, Prinstein MJ. Non-suicidal self-injury among adolescents: diagnostic correlates and relation to suicide attempts. Psychiatry Res 2006;144: $65-72$.

42. Jacobson CM, Muehlenkamp JJ, Miller AL, Turner B. Psychiatric impairment among adolescents engaging in different types of deliberate self-harm. J Clin Child Adolesc Psychol 2008;37:363-75.

43. Evans C, Lacey JH. Multiple self-damaging behaviour among alcoholic women. A prevalence study. Br J Psychiatry 1992;161:643-7.

44. Evren C, Sar V, Evren B, Dalbudak B. Self-mutilation among male patients with alcohol dependency: the role of dissociation. Compr Psychiatry 2008;49:489-95.

45. Klonsky ED, Olino TM. Identifying clinically distinct subgroups of self- injurers among young adults: a latent class analysis. J Consult Clin Psychol 2008;76:22-7.

46. Pattison EM, Kahan J. The deliberate self-harm syndrome. Am J Psychiatry 1983;140:867-72.

47. Stanley B, Winchel R, Molco A, Simeon D, Stanley $M$. Suicide and the self-harm continuum: phenomenological and biochemical evidence. Int Rev Psychiatry 1992;4:149-55.

48. Whitlock J, Knox KL. The relationship between selfinjurious behavior and suicide in a young adult population. Arch Pediatr Adolesc Med 2007;161:634-40.

49. Whitlock J, Muehlenkamp JJ, Eckenrode J. Variation in non-suicidal self-injury: identification and features of latent classes in a college population of emerging adults. J Clin Child Adolesc Psychol 2008;37:725-35.

50. Muehlenkamp JJ. Self-injurious behavior as a separate clinical syndrome. Am J Orthopsychiatry 2005;75:1-10.

51. Klonsky ED. The functions of deliberate self-injury: a review of the evidence. Clin Psychol Rev 2007;27:226-39.

52. Walsh BW, Rosen PM. Self-mutilation: theory, research, and treatment. New York: Guilford Press; 1988.

53. Favazza AR, Conterio K. Female habitual self-mutilators. Acta Psychiatr Scand 1989;79:238-89.

54. Spicer R, Miller T. Suicide acts in 8 states: incidence and case fatality rates by demographics and method. Am J Public Health 2000;90:1885-91.

55. Kessler RC, Berglund P, Borges G, Nock MK, Wang PS. Trends in suicide ideation, plans, gestures, and attempts in the United States, 19901992 to 2001-2003. JAMA 2005;293:2487-95.

56. Centers for Disease Control and Prevention. Webbased injury statistics query and reporting system (WISQARS) (2005). Available at http://www.cdc.gov/injury/wisqars/. Accessed 30 July 2009.

57. Klonsky ED, Muehlenkamp JJ. Self-injury: a re- 
search review for the practitioner. J Clin Psychol 2007;63:1045-56.

59. Muehlenkamp JJ, Engel SG, Wadeson A, et al. Emotional states preceding and following acts of non-suicidal self-injury in bulimia nervosa patients. Behav Res Ther 2009;47:83-7.

58. Denning DG, Conwell Y, King D, Cox C. Method choice, intent and gender in completed suicide. Suicide Life Threat Behav 2000;30:282-8.

60. Joiner TE. Why people die by suicide. Cambridge, MA: Harvard University Press; 2005.

61. Rudd MD, Joiner TE, Rajab MH. Treating suicidal behavior: An effective, time-limited approach. New York: Guilford Press; 2001.

62. Haw C, Houston K, Townsend E, Hawton K. Deliberate self harm patients with depressive disorders: treatment and outcome. J Affect Disord 2002; 70:57-65.

63. Muehlenkamp JJ, Gutierrez P. An investigation of differences between self-injurious behavior and suicide attempts in a sample of adolescents. Suicide Life Threat Behav 2004;34:12-23.

64. Wedig MM, Nock MK. Parental expressed emotion and adolescent self-injury. J Am Acad Child Adolesc Psychiatry 2007;46:1171-8.

65. Nixon MK, Cloutier P, Jansson SM. Nonsuicidal self-harm in youth: a population-based survey. Can Med Assoc J 2008;178:306-12.

66. Hilt LM, Cha CB, Nolen-Hoeksema S. Nonsuicidal self-injury in young adolescent girls: moderators of the distress-function relationship. J Consult Clin Psychol 2008;76:63-71.

67. Heath NL, Schaub K, Holly S, Nixon MK. Selfinjury today: review of population and clinical studies in adolescents. In Nixon MK, Heath NL, eds. Self-injury in youth: the essential guide to assessment and intervention. New York: Routledge; 2008.

68. Ross S, Heath N. A study of the frequency of self-mutilation in a community sample of adolescents. J Youth Adolesc 2002;31:66-77.

69. Zanarini MC. Zanarini rating scale for borderline personality disorder (ZAN-BPD): a continuous measure of DSM-IV borderline psychopathology. J Pers Disord 2003;17:233-43.

70. Sansone RA, Gaither GA, Songer DA. Self-harm behaviors across the life cycle: a pilot study of inpatients with borderline personality disorder. Compr Psychiatry 2002;43:215-8.

71. Whitlock JL, Powers JP, Eckenrode JE. The virtual cutting edge: adolescent self-injury and the Internet. Dev Psychol 2006;42:407-17.

72. Fortune S, Sinclair J, Hawton K. Help-seeking before and after episodes of self-harm: a descriptive study in school pupils in England. BMC Public Health 2008;8:369-81.

73. Wallenstein MB, Nock MK. Physical exercise for the treatment of non-suicidal self-injury: evidence from a single-case study. Am J Psychiatry 2007;164: $350-1$.

74. Nafisi N, Stanley B. Developing and maintaining the therapeutic alliance with self-injuring patients. J Clin Psychol 2007;63:1069-79.

75. Miller WR, Rollnick S. Motivational interviewing: preparing people to change, 2nd ed. New York: Guilford Press; 2002.

76. Kress VE, Hoffman RA. Non-suicidal self-injury and motivational interviewing: enhancing readiness for change. J Mntl Hlth Couns 2008;30:311-29.

77. Muehlenkamp JJ. Empirically supported treatments and general therapy guidelines for non-suicidal selfinjury. J Mntl Hlth Couns 2006;28:166-85.

78. Linehan MM. Validation and psychotherapy. In Bohart A, Greenberg LS, eds. Empathy reconsidered: new directions. Washington DC: American Psychological Association; 1997.

79. Skegg K. Self-harm. Lancet 2005;366:1471-83.

80. Lloyd E, Kelley ML, Hope T. Self-mutilation in a community sample of adolescents: descriptive characteristics and provisional prevalence rates. Paper presented at the Annual Meeting of the Society for Behavioral Medicine, New Orleans, Louisiana, April 2007.

81. Sansone RA, Wiederman MW, Sansone LA. The self-harm inventory (SHI): development of a scale for identifying self-destructive behaviors and borderline personality disorder. J Clin Psychol 1998; 54:973-83.

82. Gutierrez PM, Osman A, Barrios FX, Kopper BA. Development and initial validation of the SelfHarm Behavior Questionnaire. J Pers Assess 2001; 77:475-90.

83. Linehan MM, Comtois KA, Brown MZ, Heard HL, Wagner A. The suicide attempt self-injury interview: development, reliability, and validity of a scale to assess suicide attempts and intentional selfinjury. Psychol Assess 2006;18:303-12.

84. Nock MK, Holmberg EB, Photos VI, Michel BD. Self-Injurious Thoughts and Behaviors Interview: development, reliability, and validity in an adolescent sample. Psychol Assess 2007;19:309-17.

85. Nock MK, Wedig MW, Janis IB, Deliberto TL. Evidence-based assessment of self-injurious thoughts and behaviors. In Hunsley J, Mash EJ, eds. A guide to assessments that work. New York: Oxford University Press; 2008.

86. University of Washington. Behavioral Research and Therapy Clinics [Homepage.] Available at http://depts.washington.edu/brtc. Accessed 14 January 2010.

87. Osuch EA, Noll JG, Putnam FW. The motivations for self-injury in psychiatric inpatients. Psychiatry 1999;62:334-45.

88. Claes L, Vandereycken W. Self-injurious behavior: differential diagnosis and functional differentiation. Compr Psychiatry 2007;48:137-44. 
89. Abraham PF, Shirley EF. (2006). New mnemonic for depressive symptoms. Am J Psychiatry 2006;163:329_ 30.

90. Kettlewell C. Skin game: a cutter's memoir. New York: St. Martin's Press; 1999.

91. Fagin L. Repeated self-injury: perspectives from general psychiatry. Adv Psychiatr Trt 2006;12:193201.

92. Roth A, Ostroff R, Hoffman R. Naltrexone as a treatment for repetitive self-injurious behaviour: an open label trial. J Clin Psychiatry 1996;57:233-7.

93. Griengl H, Sendera A, Dantendorfer K. Naltrexone as a treatment of self-injurious behaviour. A case report. Acta Psychiatr Scand 2001;103:234-6.

94. Oquendo MA, Mann JJ. The biology of impulsivity and suicidality. Psychiatr Clin North Am 2000;23: 11-23.

95. Winchel RM, Stanley M. Self-injurious behavior: a review of the behavior and biology of self-mutilation. Am J Psychiatry 1991;148:306-17.

96. Chengappa KNR, Ebeling T, Kang JS, Levine J, Parepally H. Clozapine reduces severe self-mutilation and aggression in psychotic patients with borderline personality disorder. J Clin Psychiatry 1999; 60:477-84.

97. Ferreri M, Loze J, Rouillon F, et al. Clozapine treatment of a borderline personality disorder with severe self-mutilating behaviours. Eur Psychiatry 2004;19:177-8.

98. Chengappa RNK, Rathore D, Levine J, et al. Topiramate as add-on treatment for patients with bipolar mania. Bipolar Disord 1999;1:42-53.

99. Cassano P, Lattanzi L, Pini S, Dell'Osso L, Battistini G, Cassano GB. Topiramate for self-mutilation in a patient with borderline personality disorder. Bipolar Disord 2001;3:161.

100. Clarkin JF, Yeomans FE, Kernberg OF. Psychotherapy for borderline personality. Hoboken, NJ: Wiley; 1999.

101. Kernberg OF. The couch at sea: psychoanalytic studies of group and organizational leadership. Int J Group Psychother 1984;34:5-23.

102. Levy KN, Yeomans F, Diamond D. Psychodynamic treatments of self-injury. J Clin Psychology 2007;63:1105-20.

103. Clarkin JF, Foelsch PA, Levy KN, Hull JW, Delaney JC, Kernberg OF. The development of a psychodynamic treatment for patients with borderline personality disorders: a preliminary study of behavioral change. J Pers Disord 2001;15:487-95.

104. Levy KN, Kelly KM, Meehan KB, et al. Change in attachment patterns and reflective function in a randomized control trial of transference focused psychotherapy for borderline personality disorder. J Consult Clin Psychol 2006;74:1027-40.

105. Clarkin JF, Levy KN, Lenzenweger MF, Kernberg OF. A mulitwave RCT evaluating three treatments for borderline personality disorder. Am J Psychiatry 2007;164:1-8.

106. Bateman AW, Fonagy P. Effectiveness of partial hospitalization in the treatment of borderline personality disorder: a randomized controlled trial. Am J Psychiatry 1999;156:1563-9.

107. Bateman AW, Fonagy P. Psychotherapy for borderline personality disorder: mentalization-based treatment. Oxford: Oxford University Press; 2004.

108. Bateman AW, Fonagy P. 8-year follow-up of patients treated for borderline personality disorder: mentalization-based treatment versus treatment as usual. Am J Psychiatry 1999;165:631-8.

109. Evans K, Tryer P, Catalan J, et al. Manual assisted cognitive-behavioral therapy: a randomized controlled trial of a brief intervention with bibliotherapy for deliberate self-harm. Psychol Med 1999;29: 19-25.

110. Tryer P, Thompson S, Schmidt U, et al. Randomized controlled trial of a brief cognitive-behavioural therapy versus treatment as usual for recurrent deliberate self-harm: the POMPACT study. Psychol Med 2003;33:969-96.

111. Ogata SN, Silk KR, Goodrich S, Lohr NE, Westen D, Hill EM. Childhood sexual and physical abuse in adult patients with borderline personality disorder. Am J Psychiatry 1990;147:1008-13.

112. Herman JL, Perry JC, van der Kolk BA. Childhood trauma in borderline personality disorder. Am J Psychiatry 1990;146:490-5.

113. Paris J, Zweig-Frank H. A critical review of the role of childhood sexual abuse in the etiology of borderline personality disorder. Can J Psychiatry 1992;37: 125-8.

114. Muehlenkamp JJ, Kerr PL. Abuse subtypes and non-suicidal self-injury: preliminary evidence of complex emotion regulation patterns. J Nerv Ment Dis. In press.

115. Klonsky ED, Moyer A. Childhood sexual abuse and non-suicidal self-injury: meta-analysis. Br J Psychiatry 2008;192:166-70.

116. Linehan MM. Skills training manual for treating borderline personality disorder. New York: Guilford Press; 1993.

117. Linehan MM, Armstrong HE, Suarez A, Allmon D, Heard H. Cognitive-behavioral treatment of chronically parasuicidal borderline patients. Arch Gen Psychiatry 1991;48:1060-4.

118. Linehan MM, Heard H, Armstrong HE. Naturalistic follow-up of a behavioral treatment for chronically suicidal borderline patients. Arch Gen Psychiatry 1993;50:971-4.

119. Koons CR, Robins CJ, Tweed JL, et al. Efficacy of dialectical behavior therapy in women veterans with borderline personality disorder. Behav Ther 2001; 32:271-90.

120. Linehan MM, Comtois KA, Murray AM, et al. Two-year randomized controlled trial and fol- 
low-up of dialectical behavior therapy vs. therapy by experts for suicidal behaviors and borderline personality disorder. Arch Gen Psychiatry 2006;63: 757-66.

121. Barley WD, Buie SE, Peterson EW, et al. Development of an inpatient cognitive-behavioral treatment program for borderline personality disorder. J Pers Disord 1993;7:232-40.

122. Bohus M, Haaf B, Simms T, et al. Effectiveness of inpatient dialectical behavior therapy for borderline personality disorder: a controlled trial. Behav Res Ther 2004;42:487-99.

123. Rathus J, Miller AL. Dialectical behavior therapy adapted for suicidal adolescents. Suicide Life Threat Behav 2002;32:146-57.

124. Rathus J, Miller AL, Linehan MM. Dialectical be- havior therapy with suicidal adolescents. New York: Guilford Press; 2006.

125. Miller AL, Rathus JH, Linehan MM, Wetzler S, Leigh E. Dialectical behavior therapy adapted for suicidal adolescents. J Psychiatr Pract 1997;3:7886.

126. Katz L, Cox BJ, Gunasekara S, Miller AL. Feasibility of dialectical behavior therapy for suicidal adolescent inpatients. J Am Acad Child Adolesc Psychiatry 2004;43:276-82.

127. Kerr PL, Muehlenkamp JJ, Larsen AM. Implementation of DBT-informed therapy at a rural training clinic: a case study. Cogn Behav Pract 2009;16:92100.

128. Lofthouse N, Yaeger-Schweller J. Nonsuicidal selfinjury and suicide risk among adolescents. Curr Opin Pediatr 2009;21:641-5. 